\title{
Atomic Force Microscopy-indentation demonstrates that Alginate Beads are $\underline{\text { mechanically stable under Cell Culture Conditions }}$
}

Chih-Yao Chui ${ }^{1} \ddagger$, Andrea Bonilla-Brunner ${ }^{2} \ddagger$, Jacob Seifert ${ }^{2,3}$, Sonia Contera ${ }^{2 *}$ and Hua $\mathrm{Ye}^{1^{*}}$

${ }^{1}$ Institute of Biomedical Engineering, Department of Engineering Science, University of Oxford, Old Road Campus off Roosevelt Drive, OX3 7DQ

${ }^{2}$ Clarendon Laboratory, Department of Physics, University of Oxford, Parks Road, OX1 3PU

${ }^{3}$ Department of Plant Sciences, University of Oxford, South Parks Road, OX1 3RB

‡ These authors contributed equally

Keywords: Alginate microbeads, Atomic force microscopy, Mechanical properties, Reduced elastic modulus, Bead swelling, microindentations.

\section{Corresponding Authors}

\section{$\underline{\text { Sonia Contera }}$}

Email: sonia.antoranzcontera@physics.ox.ac.uk

Telephone: +44(0)1865 272269

$\underline{\text { Hua Ye }}$

Email: hua.ye@eng.ox.ac.uk

Telephone: +44(0)1865617689 


\section{Abstract}

Alginate microbeads are extensively used in tissue engineering as microcarriers and cell encapsulation vessels. In this study, we used atomic force microscopy (AFM) based indentation using $20 \mu \mathrm{m}$ colloidal probes to assess the local reduced elastic modulus ( $\mathrm{E}^{*}$ ) using a novel method to detect the contact point based on the principle of virtual work, to measure microbead mechanical stability under cell culture conditions for 2 weeks. The bead diameter and swelling were assessed in parallel. Alginate beads swelled up to $150 \%$ of their original diameter following addition of cell culture media. The diameter eventually stabilized from day 2 onwards. This behaviour was mirrored in $\mathrm{E}^{*}$ where a significant decrease was observed at the start of the culture period before stabilization was observed at $\sim 2.1 \mathrm{kPa}$. Furthermore, the mechanical properties of freeze dried alginate beads after re-swelling them in culture media were measured. These beads displayed vastly different structural and mechanical properties compared those that did not go through the freeze drying process, with around $125 \%$ swelling and a significantly higher $\mathrm{E}^{*}$ at values over $3 \mathrm{kPa}$. 


\section{Introduction}

Alginate is a natural polysaccharide derived from brown seaweed that consists of linear binary copolymers of a-D-mannuronic acid (M block) and b-L-guluronic acid (G block) residues in varying proportions, arranged in MM and GG blocks scattered with MG blocks (Rowley and Mooney, 2002). Alginate is widely used as a hydrophilic biopolymeric material in biomedical research due to its capacity to be ionically crosslinked by divalent ions such as $\mathrm{Ca}^{2+}$ to form a gel under mild conditions without external heating or using strong organic chemicals (Bidarra et al., 2014; Hari et al., 1996; Wilson and McDevitt, 2013). Being a hydrogel, alginate can absorb water up to thousand times its dry weight, which reduces mechanical friction in vivo on surrounding tissue (Hoffman, 2012). Alginate also possesses similar physiochemical properties to the native extracellular matrix (Hoare and Kohane, 2008) and acts as a semi permeable membrane allowing diffusion of nutrients and oxygen to cells while protecting them from mechanical stresses as well as the host's immune system (Orive et al., 2004).

Alginate is widely used to make hydrogel microbeads in the presence of calcium cations via ionotropic gelation. These microbeads are commonly used in cell encapsulation for bioartificial livers (Dore, 1999) and monoclonal antibody production (Shirai et al., 1987). Additionally, alginate based microcarriers have also been developed (Gröhn et al., 1997).

There are several concerns about the stability of the beads in in vitro studies due to non-gelling monovalent ions such as $\mathrm{Na}^{+}$present in cell culture environments (Darrabie et al., 2006; Tay et al., 1993). These ions exchange with $\mathrm{Ca}^{2+}$ within the bead altering the bead integrity, which leads to swelling, rupture and eventually, the dissolution of the beads and a premature release of the cells. Furthermore, changes in microbead properties could alter the final condition of cells as it has been shown that the material's mechanical properties have a strong influence on 
cell phenotype (Discher, 2005; Engler et al., 2006; Ghasemi-Mobarakeh, 2015; Guilak et al., 2009; Saha et al., 2008).

To ensure long term culture, it is essential to understand stability, swelling behaviour and the mechanical properties of alginate microbeads under cell culture conditions. Previous reports have detailed these characteristics of alginate beads in buffer saline (Bajpai and Sharma, 2004; Darrabie et al., 2006; Mørch et al., 2006; Pasparakis and Bouropoulos, 2006; Yuan et al., 2012) or water (Chan et al., 2011; Wang et al., 2005). However, very few studies have measured these parameters in cell culture media (Gaumann et al., 2000). Despite the similarities between these buffers, there are significant differences in the salt content between the buffer solutions and cell culture media, which could lead to different swelling behaviour or surface mechanical properties.

Bead mechanical stiffness has been previously investigated by measuring the bulk properties typically using a texture analyser (Chan et al., 2011; Gugerli et al., 2002; Wang et al., 2005) or micropipette aspiration (Kleinberger et al., 2013). Bulk properties are determined by measurement of the mechanical properties at the millimetre scale or greater. However, cells feel the matrix they are attached to in the micron and nanometre scales and receive exogenous forces from the surface environment at those scales — which is an important effector of cell behaviour (Handorf et al., 2015; Rehfeldt et al., 2007). Measurements at the micron and nanoscale scale can be achieved by application of local nanoNewton (nN) forces via indentation experiments using AFM (Markert et al., 2013). In addition, AFM measurements can be performed in a liquid environment mimicking a cell culture system (Rehfeldt et al., 2007).

AFM indentations have been used to characterise the mechanical properties of hydrogel scaffolds for tissue engineering (Markert et al., 2013); alginate-based 3D scaffolds for tissue- 
engineered cartilage constructs (Tomkoria et al., 2007), as well as for investigating the correlation of matrix stiffness with breast cancer cellular activity (Cavo et al., 2016). AFM indentations have also been performed on alginate beads however, the indentations were not performed in cell culture conditions (Helfricht et al., 2017; Lekka et al., 2004; Patel et al., 2016). Moreover, most of these studies focus on the surface topography (Patel et al., 2016) or adhesion of the beads (Helfricht et al., 2017) and relatively few studies investigated the mechanical properties of the microbeads (Lekka et al., 2004). Furthermore, none of the studies mentioned above measured beads of a diameter suitable for cell encapsulation or microcarrier use. Alginate microbeads are typically around 200-400 $\mu \mathrm{m}$ in diameter for cell encapsulation, in order to provide adequate diffusion of oxygen to the cells within the beads (Drury and Mooney, 2003; Gasperini et al., 2013; Lee and Mooney, 2012). Similarly, microcarriers are typically between 90-300 $\mu \mathrm{m}$ in diameter (Freshney, 2011; Szczypka et al., 2014) to maximize surface area to volume ratio while providing a sufficient surface area per bead to support cell growth (Chen et al., 2013; Markvicheva and Grandfils, 2004). It has been shown that the dimensions of the sample would affect the stiffness values measured via AFM (Guo et al., 2014). Hence, in order to quantify bead stability during cell encapsulation and microcarrier applications, it is vital to perform indentations in a cell culture environment with suitably sized beads.

In this study, our first objective is to use AFM-indentation to quantify the variations in the reduced Young's modulus ( $\left.\mathrm{E}^{*}\right)$, diameter and swelling of alginate beads of roughly $300 \mu \mathrm{m}$, suitable for both cell encapsulation as well as microcarrier applications. The measurement in cell culture media was over a period of 2 weeks which is the typical amount of time required in stem-cell culture (Lechanteur, 2014; Lee et al., 2010; Serra et al., 2011) for cell therapy. 
Freeze drying is employed within the food and pharmaceutical industry for long term preservation and storage. The process involves removing water from a material through sublimation (Barley, n.d.). Successful freeze drying could extend shelf life and provide a pathway towards commercialization for the alginate microbeads (Labconco, 2010). It was previously shown that the porous gel networks of alginate beads could be preserved following freeze drying (Liu et al., 2016). However, freeze dried beads are more fragile in their dry state (Choi et al., 2002) and have been shown to be mechanically weaker compared to vacuum dried alginate beads during compression tests (Gal and Nussinovitch, 2007). Because of this, we used AFM indentation to identify changes in $\mathrm{E}^{*}$ of rehydrated freeze dried alginate beads compared to freshly made counterparts, along with the effects of freeze drying in the bead re-swelling processes.

\section{Materials and Methods}

\subsection{Alginate Microbeads Preparation by Electrospraying}

Medium viscosity alginate (A2033, M/G ratio 1.56) (Sigma Aldrich, USA) was dissolved in a $0.9 \%(\mathrm{w} / \mathrm{v})$ sodium chloride solution to obtain an alginate solution of $1 \%(\mathrm{w} / \mathrm{v})$. Alginate beads were electrosprayed by passing the solution through a $30 \mathrm{G}$ blunt needle at $3 \mathrm{ml} / \mathrm{min}$ with an applied voltage of $7.5 \mathrm{kV}$ and electrode distance $2.5 \mathrm{~cm}$. Alginate microdroplets were gelled 
into beads in a $0.1 \mathrm{M}$ calcium chloride bath for 1 hour. The electrospraying setup is shown in Figure 1.

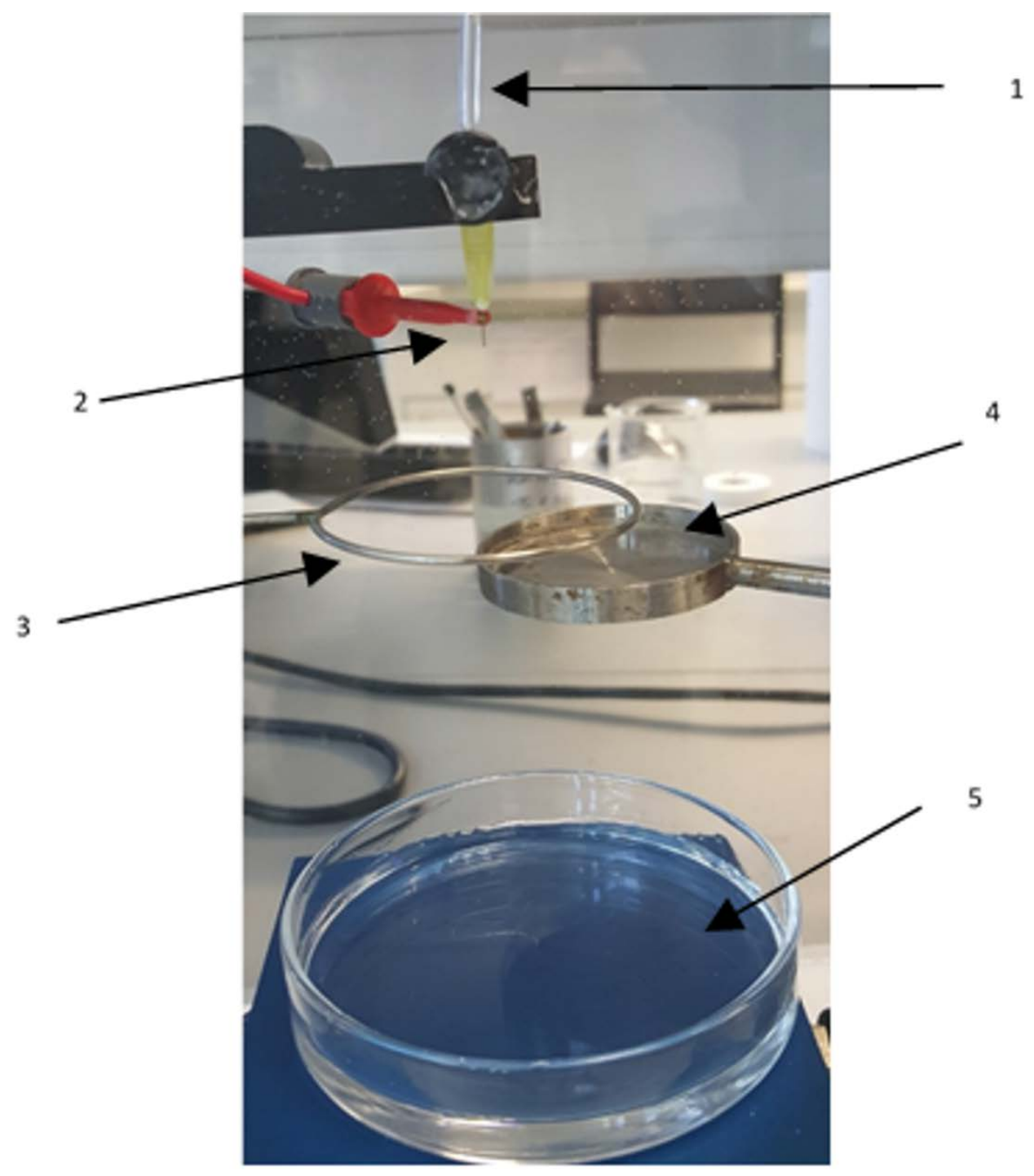

Figure 1. Electrospraying setup.1) Alginate supply from syringe pump, 2) positive electrode attached to blunted needle, 3) ground ring electrode, 4) rotatable metal dish to catch initial droplets before a continuous jet was formed, 5) calcium chloride gelling bath.

\subsection{Freeze Drying Beads}

Alginate beads were suspended in $2 \mathrm{ml}$ of deionized water at 13000 beads/ml within a 6 well plate. The beads were frozen down to $-40{ }^{\circ} \mathrm{C}$ at $100 \mathrm{mtorr}$ before being freeze dried for $400 \mathrm{~min}$ at 200 mtorr. The temperature was ramped to $-20^{\circ} \mathrm{C}$ at 200 mtorr over 100 minutes. Finally, 
the temperature of the sample was ramped to $20{ }^{\circ} \mathrm{C}$ over the next 100 minutes. Freeze drying was conducted using a BPS Genisis II freeze dryer (SP Scientific, USA).

\subsection{Assessment of Bead Swelling}

Alginate beads were added to low glucose (1 g/l) Dulbecco's Modified Eagle’s Medium (DMEM) with $10 \%$ Foetal Bovine Serum and $0.1 \%$ Penicillin-Streptomycin. The beads were left in DMEM of 24 hours a period referred to as the conditioning period. Following this, the images of beads were captured using a Nikon TiE 2000 (Japan) fluorescence microscope. The bead diameters of 30 beads were measured each day using ImageJ (National Institutes of Health, USA), with the first measurement known as day 1 for a total of 14 days. Culture media was changed every $3^{\text {rd }}$ day to mimic cell culture protocol.

\subsection{AFM Indentation experiments}

In order to consider an average $\mathrm{E}^{*}$ of the alginate beads in DMEM, a $20 \mu \mathrm{m}$ polystyrene bead (Sigma-Aldrich, 74491) (Young's modulus (E) = 3 GPa) was glued to a Scanasyst-fluid+ cantilever (spring constant $\mathrm{k}=$ 0.7-1.4 N/m, resonance frequency $=150 \mathrm{kHz}$, Bruker) using Flex + Bond sealant (Weicon, Germany) by indenting the glue and immediately pressing the bead until cantilever deflection was observed and setting for 5 minutes. Cantilevers were allowed to dry overnight.

Force vs. distance curves were obtained with a commercial MFP-3D AFM and Igor Pro Asylum Research version 14.16.136 (Asylum Research, Santa Barbara, CA). The alginate beads in DMEM medium were placed on a cover slide previously treated with 70 \% ethanol. The cantilever was positioned on the highest part of an alginate microbead by observing the piezo extension/retraction whilst moving the stage in both $\mathrm{x}$ and $\mathrm{y}$ direction. 
Fast indentations of the beads were performed $(45 \mu \mathrm{m} / \mathrm{s})$ to minimise the time-dependent behaviour of the beads due to viscoelasticity or poroelasticity. A force trigger point of $70 \mathrm{nN}$ was used to indent 30 beads, 50 times each. Indentations were conducted on day 1, day 5, day 8, day 12 and day 14.

In order to ensure minimal bead movement during the indentations and avoid significant changes in the contact angle and indentation area, the initial position of the piezo was observed prior indentation. In the case where bead movement was observed, the 50 indentations were reinitiated to ensure reproducibility.

\subsection{Fitting procedure to extract elastic modulus}

$\mathrm{E}^{*}$ is often used to describe the mechanical properties of biological structures because it is an intensive property, independent of geometry. It is defined as (Johnson, 1985)

$$
E^{*}=\frac{E}{1-v^{2}}
$$

Where E is the Young's Modulus structure and v represents the Poisson's ratio of the structure. (The Poisson's ratio of the alginate beads is unknown; hence we have chosen to report E*.)

In AFM nanoindentation experiments $\mathrm{E}^{*}$ is usually extracted from force vs. indentation curves, by using continuum mechanics models where the relation between the force (F) and indentation $(\delta)$ is:

$$
F(\delta)=g E^{*} \delta^{\gamma}
$$

Where g and $\gamma$ depend on the AFM tip geometry (e.g. in the Hertz model for spherical indenters of radius $R$, such as those used here, $g=4 / 3 R^{1 / 2}, \gamma=3 / 2$ ) 
The typical AFM force vs indentation curve (force curve) contains a flat region before the indentation regime where the cantilever is deflected as it contacts with the sample, however experimental noise makes the exact determination of the contact point difficult. Many methods have been developed to determine the contact point (Gavara, 2016) but they are specific for certain systems and not accurate enough for general applications.

Here we develop and apply a new, general method based on the principle of virtual work, where the contact point was determined by the point where the virtual work was minimised. This determines the point of first deflection caused by any repulsive interaction. With this approach we were able to find an analytical solution independently from the experimental system, which makes it widely applicable (details for this derivation are available in the appendix).

Indentation curves were fitted using Hertz Model (Landau and Lifshitz, 1970) (equation 2) of a plane being indented by a sphere (it is a valid approximation if we consider the diameter of the alginate bead to be around $300 \mu \mathrm{m}$ and more than 10 times bigger than the $20 \mu \mathrm{m}$ polystyrene bead attached to the cantilever tip:

$$
\mathrm{F}(\delta)=\frac{4}{3} \mathrm{E}^{*} \mathrm{R}^{1 / 2} \delta^{3 / 2}
$$

Contact point determination and Hertz fittings were performed using a custom-build analysis code implemented in Python 3.6.5.

\subsection{Statistical Analysis}

A two way ANOVA $(\mathrm{p}<0.05)$ was used to determine significance in $\mathrm{E}^{*}$ and bead diameter of freshly made beads and freeze dried beads during the two week measurement period. A posthoc Tukey test was used to identify the significance. 
Bootstrapping was performed on the stiffness values in order to estimate the standard error of the mean. Each bootstrap contained 30 samples from the data with replacement, a total of 100 bootstraps were performed.

\section{Results}

\subsection{Bead Swelling}

The spherical alginate microbeads created via electrospraying are shown in Fig. 2A in an optical microscopy image, with a diameter of $217 \pm 20 \mu \mathrm{m}$ on average (mean \pm standard deviation). The beads swelled to an average of $310 \pm 20 \mu \mathrm{m}$ upon addition of DMEM (Fig. 2B). Upon freeze drying, the beads shrunk into small spheres which appeared to clump together with an average diameter of $90 \pm 10 \mu \mathrm{m}$ (Fig 2C) however, the beads re-swelled into distinct spherical beads of diameter of $267 \pm 10 \mu \mathrm{m}$ following addition of DMEM (Fig. 2D).

Freshly made beads displayed significant swelling of the bead from day 1 to day 2 (Fig 3). However, the bead size remained stable over the rest of the measurement period. This initial swelling was also observed in the freeze-dried beads however, the diameter on day 2 was still significantly smaller compared to the diameter of day 8, 10, 11 and 14 (Fig 3). After day 2, the bead size remained stable. Finally, bead diameter of the re-swelled freeze-dried beads was significantly smaller compared to the freshly made beads (Fig 3) on all of the days. 


\section{A}

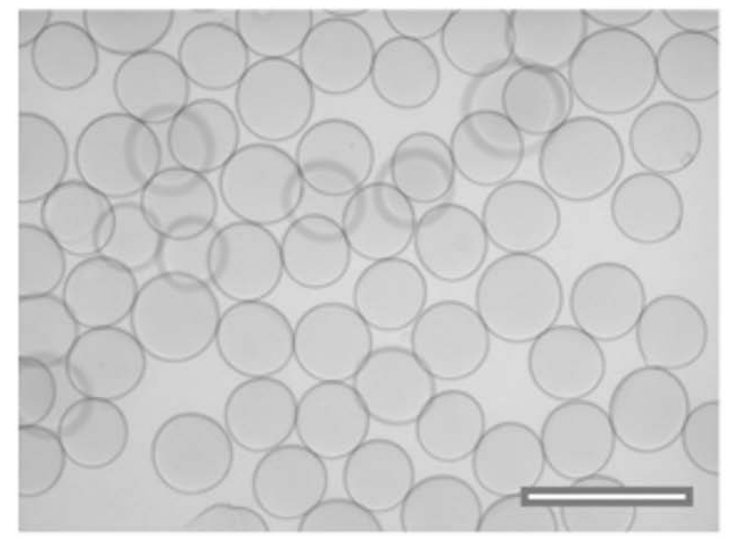

\section{B}

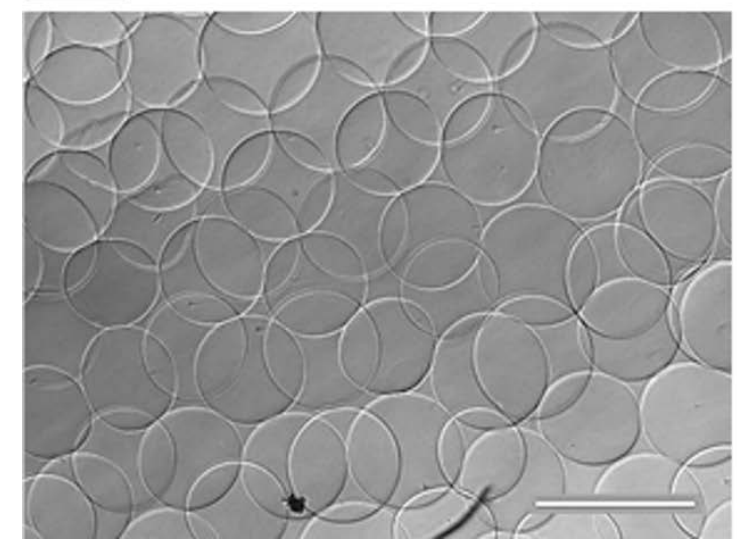

\section{C}

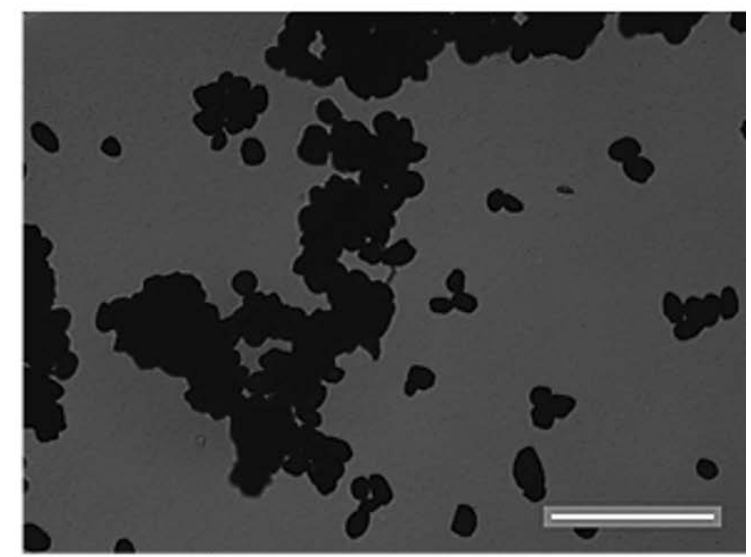

\section{D}

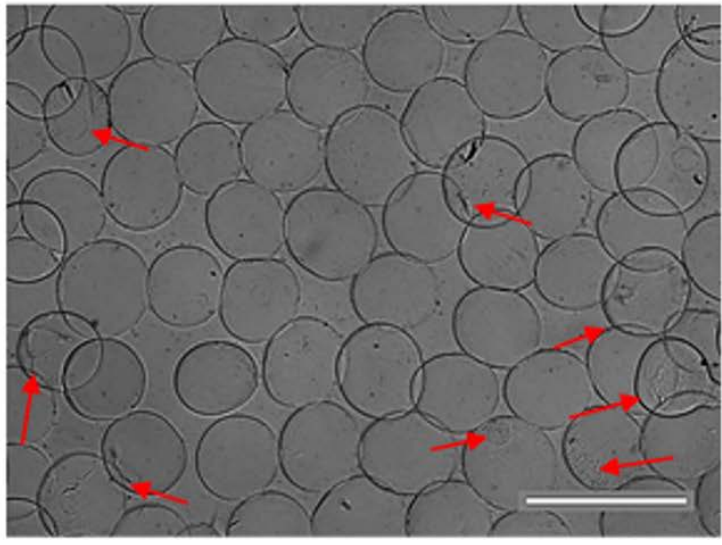

Figure 2. Changes in bead size and morphology under different conditions observed with optical microscopy. A) Alginate beads in calcium chloride solution created by electrospraying, B) Swelling of alginate beads upon immersing in DMEM media for 24 hours, C) Freeze dried alginate beads, D) Re-swelling of the freeze dried beads upon the conditioning period of 24 hours. However, rough surfaces were observed on the beads (indicated by red arrows). Scale bar represent $500 \mu \mathrm{m}$ in all images. 


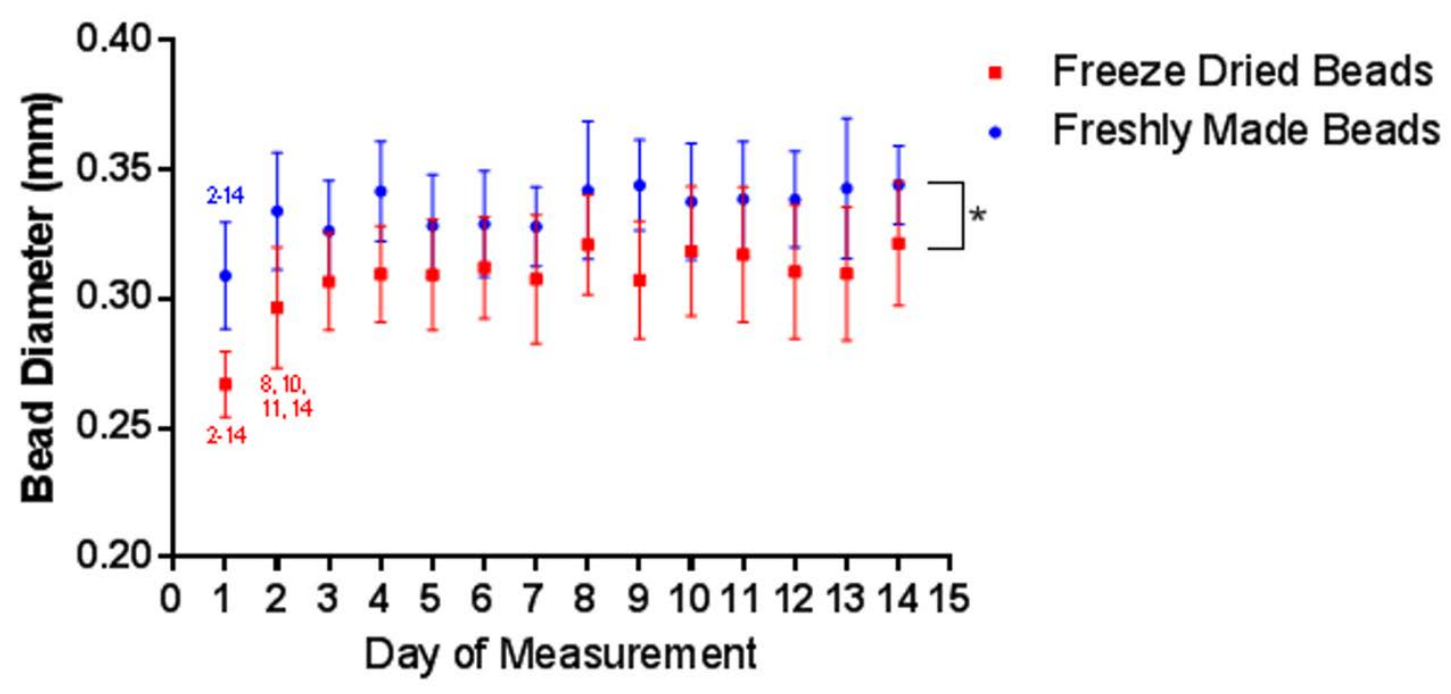

Figure 3. Bead diameter in DMEM culture media over a 14 day period. Beads were preconditioned for 24 hours before the first measurement was made. Bead swelling in freshly made beads is indicated in blue and bead swelling in freeze dried beads is indicated in red. The days in which the bead diameter is significant are shown by numbers above the measurement. * denotes the freshly made beads were significantly larger compared to the freeze dried beads. Error bars show standard deviation.

\subsection{Reduced Young's modulus ( $\left.E^{*}\right)$ of the beads}

The $\mathrm{E}^{*}$ of the beads was calculated from indentation experiments as described in the methods section. Fig. 4 shows the A) cantilever used with an attached $20 \mu \mathrm{m}$ bead, B) an example of a force/indentation curve on alginate microbeads with the contact point and the Hertz model fit 
on the trace from 10 to $400 \mathrm{~nm}$. This range of fitting was chosen since it corresponds to low forces and small indentations in order to avoid non-linear elasticity effects (Gavara, 2016).

The $\mathrm{E}^{*}$ of the freshly made beads was significantly higher on day 1 compared to the rest of the time points. However, there was no significant change in $\mathrm{E}^{*}$ over the rest of the 2-week period (Fig 5A). Compared to freshly made beads, the freeze drying process resulted in a significantly higher $\mathrm{E}^{*}$. In addition, the $\mathrm{E}^{*}$ of the freeze dried beads decreased significantly from day 8 to 12 while remaining non-significant from day 1 to 8 (Fig 5B).

The swelling and mechanical behaviour of the freshly made beads and the freeze dried beads are summarized in Table 1.
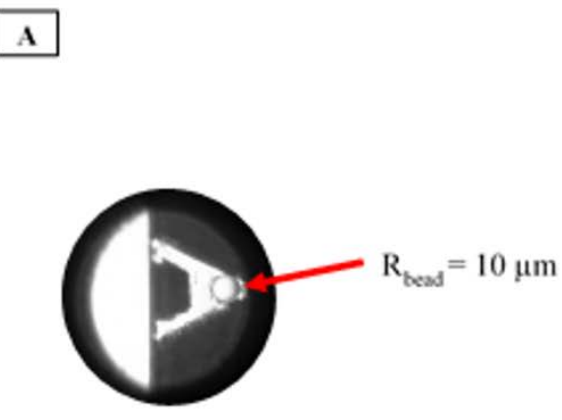

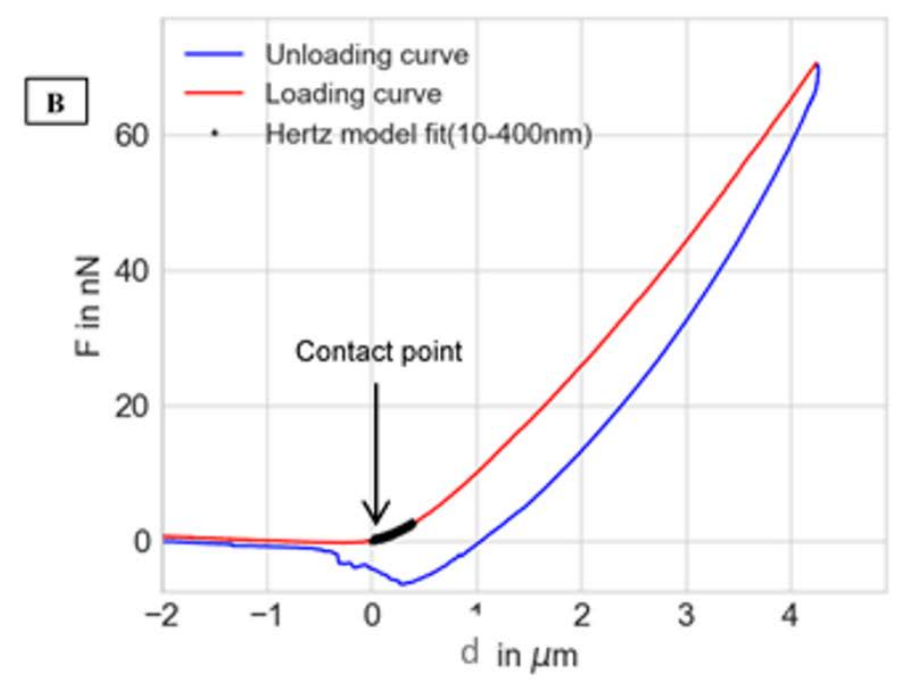

$\mathrm{d}$ in $\mu \mathrm{m}$

Figure 4. AFM- indentation experiments. A) Image of triangular cantilever with a $20 \mu \mathrm{m}$ in diameter bead attached. B) Force vs displacement (d) curve showing the contact point in the loading curve in red (when the cantilever is approaching the sample, the unloading curve in blue (when the cantilever is retracting after the contact was made) and the Hertz Model fit $10 \mathrm{~nm}$ after the contact point to $400 \mathrm{~nm}$. 


\section{A}

- BeadDianeter
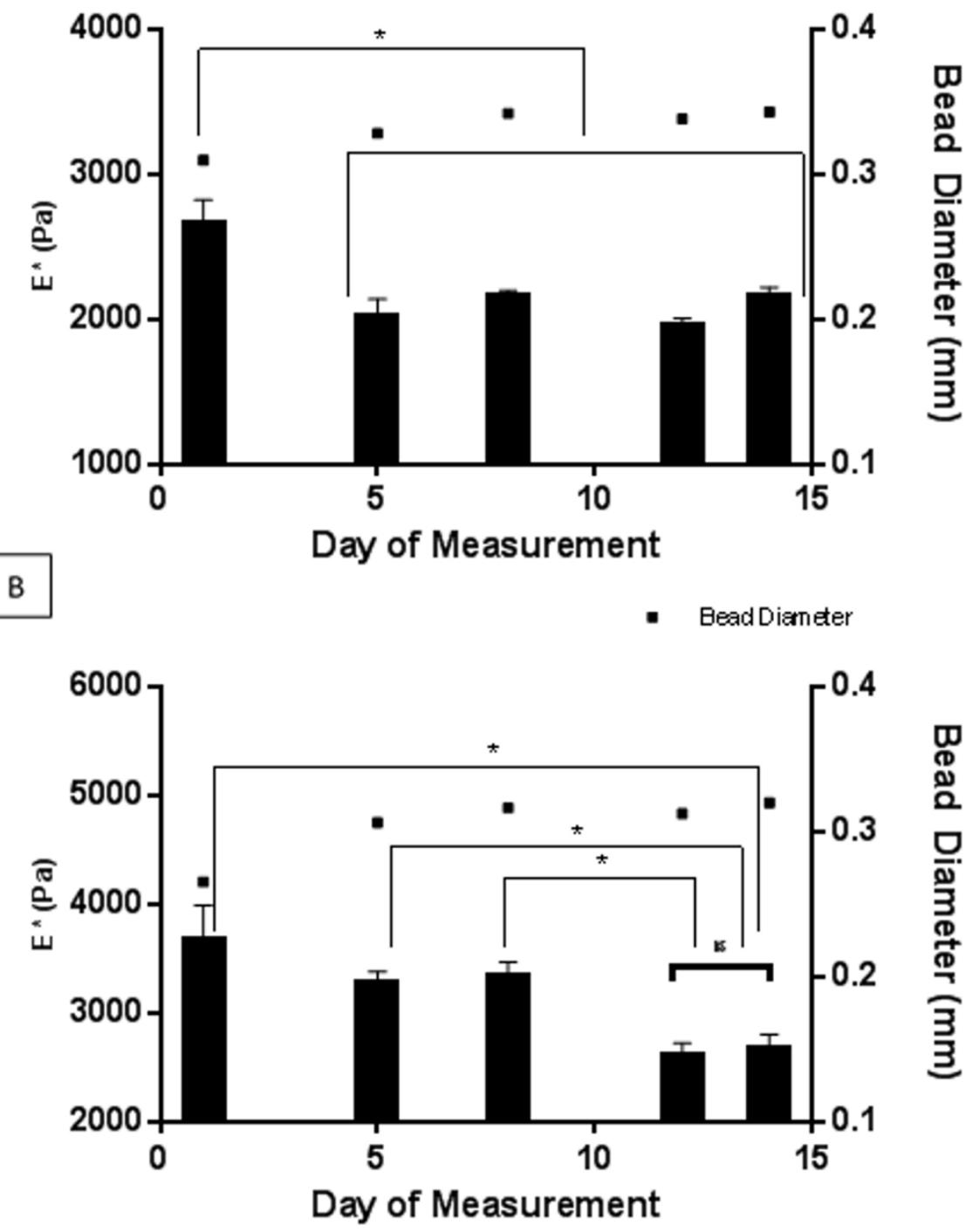

Figure 5. Reduced modulus measured on day 1, 5, 8, 10 and 14 post conditioning, of freshly made beads (A) and freeze dried beads (B). Error bars show the standard error to the mean. Bead diameter from bead swelling measurements were plotted on the secondary axis. A) $\mathrm{E}^{*}$ on day 1 was significantly higher compared to rest of the measurements denoted by *. B) $\mathrm{E}^{*}$ measured on day 1, 5 and 8 were significantly higher compared to day 12 and 14, denoted by *. 
Table 1. Summary of results from bead swelling and AFM indentation for both freshly made beads and freeze dried beads.

\begin{tabular}{|c|c|c|}
\hline Sample & Bead Swelling Result Summary & AFM Indentation Result Summary \\
\hline $\begin{array}{l}\text { Freshly } \\
\text { Made Beads }\end{array}$ & $\begin{array}{l}\text { Beads swelled significantly upon } \\
\text { immersion in media from an } \\
\text { average diameter of } 217 \mu \mathrm{m} \text { to } \\
310 \mu \mathrm{m} \text {. No significant changes } \\
\text { to bead diameter was observed } \\
\text { from day } 2-14 \text {. }\end{array}$ & $\begin{array}{l}\mathrm{E}^{*} \text { of the beads was significantly } \\
\text { higher on day } 1 \text { compared to the other } \\
\text { time points. } \mathrm{E}^{*} \text { remained stable } \\
\text { throughout the remaining time points. }\end{array}$ \\
\hline $\begin{array}{l}\text { Freeze } \\
\text { Dried Beads }\end{array}$ & $\begin{array}{l}\text { Beads swelled significantly upon } \\
\text { addition to media from } 90 \mu \mathrm{m} \text { to } \\
267 \mu \mathrm{m} \text {. No significant changes } \\
\text { to bead diameter was observed } \\
\text { from day } 3-14 \text {. }\end{array}$ & $\begin{array}{l}\text { No significant changes in } E^{*} \text { was } \\
\text { observed until day } 8 \text {. This was } \\
\text { followed by a significant decrease in } \\
\text { E* on day } 12 \text { and } 14 \text {. } \\
\text { Freeze drying resulted in a } \\
\text { significantly higher } E^{*} \text { compared to } \\
\text { freshly made beads. }\end{array}$ \\
\hline
\end{tabular}




\section{Discussion}

We measured the $\mathrm{E}^{*}$ of alginate beads using AFM-indentation experiments in order to assess the mechanical stability of these during a period of two weeks.

The 24 hour conditioning period allowed the beads to equilibrate in the medium. Moreover, this equilibration period also allowed proteins in the medium to form a coat on the surface of the bead to enable better cell attachment (Kim et al., 1992). Furthermore, in the case of the freeze dried alginate beads, this time allows beads to re-swell in the media.

\subsection{Bead Swelling}

Divalent cations such as $\mathrm{Ca}^{2+}$ interact with both $\mathrm{M}$ and $\mathrm{G}$ blocks of alginate. With $\mathrm{G}$ blocks, $\mathrm{Ca}^{2+}$ packs in the interstices between coordinated polymer chains creating a 3D network. This model is known as the "Egg-box" model and its formation causes the alginate to gel (Grant et al., 1973). However, alginate beads are susceptible towards non gelling monovalent ions such as $\mathrm{Na}^{+}$(Bajpai and Sharma, 2004) present in cell culture media. These ions make alginate beads swell and eventually dissolve (Mørch et al., 2006; Strand et al., 2002). $\mathrm{Na}^{+}$initially exchanges with $\mathrm{Ca}^{2+}$, binding to $\mathrm{M}$ groups and causing an electrostatic repulsion between $\mathrm{COO}^{-}$ groups which relaxes the chain. This allows the surrounding medium to penetrate into the bead, causing swelling and eventually $\mathrm{Ca}^{2+}$ within $\mathrm{G}$ groups are exchanged and the Egg-box structure disintegrates, breaking down the bead (Bajpai and Sharma, 2004).

In this study, $\mathrm{Ca}^{2+}$ exchange with $\mathrm{Na}^{+}$from the DMEM buffer reached equilibrium on day 2 for the freshly made beads since no further significant swelling was observed after that. A similar swelling behaviour in saline incubation has been observed previously (Darrabie et al., 2006) with rapid swelling for the first two days of incubation, followed by a constant diameter for over the 14 day period. This was not the case in PBS, where the \% weight change increased 
rapidly due to water uptake up to 60 minutes of incubation. The weight of the beads remained stable for several hours, unlike the diameter, the bead weight began to decline at around 200 minutes post incubation indicating degradation of the bead (Pasparakis and Bouropoulos, 2006). This is due to the fact that unlike saline, PBS also contains phosphate ions which destabilizes $\mathrm{Ca}^{2+}$ linkages (Nunamaker et al., 2007). Although DMEM also contains phosphates, in this study the beads remained intact by the end of the two weeks; unlike PBS, DMEM contains $\mathrm{Ca}^{2+}$ ions (Sigma-Aldrich, n.d.) which would counterbalance the ion exchange to a certain degree.

Freeze-dried beads, in contrast, appeared to equilibrate later since the diameter on day 2 was still significantly smaller compared to the diameter on days 8, 10, 11 and 14, possibly due to the incomplete re-swelling following the freeze-drying process.

The bigger diameter of the freshly made beads, compared to the re-swelled freeze-dried beads could be due to structural changes produced upon freeze drying. It is known that collapse of the hydrogel porous structure could result from the freeze drying process if the drying temperature exceeds the glass transition point of alginate beads (Barley, n.d.). However, it was unlikely that this occurred due to the low temperature of our process $\left(-40^{\circ} \mathrm{C}\right.$ slowly ramped to $-20^{\circ} \mathrm{C}$ during the drying phase); the fact that the resultant freeze dried beads remained spherical following addition of media (Fig 2E) also makes this hypothesis unlikely. Oven-dried beads have been shown to shrink and shrivel, indicating serious deformation and structural collapse (Abubakr et al., 2009; Liu et al., 2016), which differs from our findings. Shrinkage of the alginate hydrogel structure during freeze drying is expected; ice sublimation during freeze drying generates pores leading to shrinkage of the beads due to surface forces as the ice crystals leave the structure (Krokida and Karathanos, 1998). Such material shrinkage due to water loss could result in a molecular rearrangement such as increased chain entanglement arising from inter-chain interactions and H-bond formation (Domarecka et al., 2016; Sideridou et al., 2003). 
This is distinct from structural collapse which would be seen if lyophilisation were to exceed the glass transition temperature (as shown in oven-dried beads) (Rambhatla et al., 2005). Therefore a smaller bead diameter after rehydration is likely to reflect a slight compaction of the alginate polymer through lyophilisation. Thus the final diameter would be lower compared to freshly made counterparts despite further swelling of the freeze dried beads in culture media due to sodium ion exchange.

\subsection{Mechanical Properties measurement by AFM microindentation}

Changes in $\mathrm{E}^{*}$ of the beads during the two week period could be an indication of the stability of the microbeads during cell culture applications. Although bead swelling is related to the stability of the beads, mechanical properties of hydrogels normally alter prior to any physical change (Kleinberger et al., 2013) therefore, it was necessary to perform both tests in parallel.

\subsubsection{Hertz model in indentation experiments}

The compressed materials are required to be linearly elastic and follow Hooke's law for Hertz's theory to be valid (Dintwa et al., 2008). Because of this, the chosen fitting region of the force vs distance curves was chosen to be 10 to $400 \mathrm{~nm}$, since it corresponds to low forces and small indentations in order to avoid non-linear elasticity effects (Gavara, 2016) and fall within the Hertzian limit.

Alginate beads behave viscoelastically and poroelastically as the water within the beads is pushed out during the deformation of the bead. This leads to measurements being time dependent. However, it has been shown that at high compression speeds the time dependent behaviour could be neglected (Wang et al., 2005). Furthermore, the standard deviation of the $E^{*}$ values within the 50 indentations of each bead was low, with a relative standard deviation 
of roughly $10 \%$ (Fig 6), suggesting that the results were time independent, hence any viscoelastic responses could be neglected as they will be minimal compared to $\mathrm{E}^{*}$. Additionally, small dispersions in $\mathrm{E}^{*}$ values can be an indicative of the lack of bead movement in between each indentation, indicating experimental reproducibility.

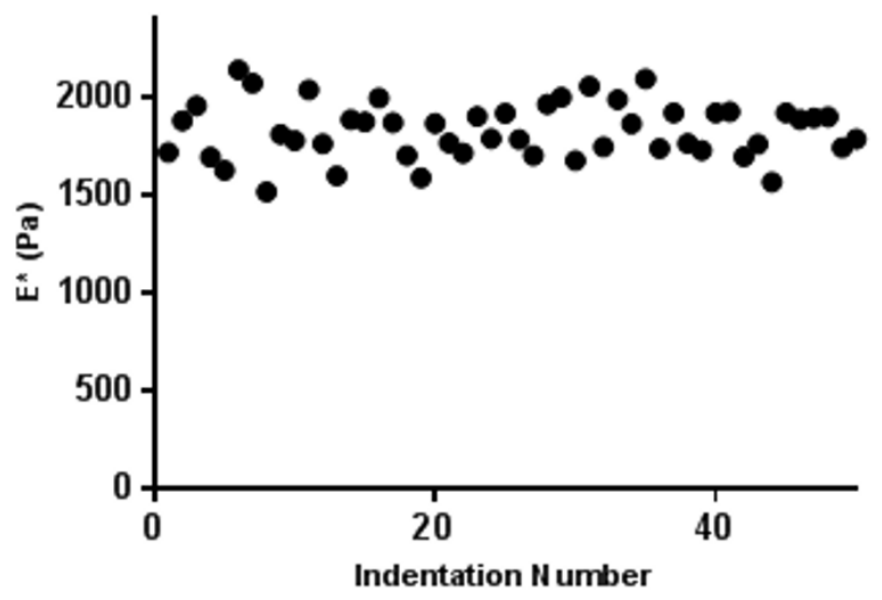

Figure 6. $\mathrm{E}^{*}$ values obtained for one alginate bead showing the small variation (roughly $10 \%$ ) within the 50 indentations made.

\subsubsection{Indentation experiments}

In the case of the freshly made beads, $\mathrm{E}^{*}$ was significantly higher on day 1 , while remaining the same for the rest of the two weeks. This is likely due to the bead size being significantly smaller on day 1 . The swelling indicates weakening of the $\mathrm{Ca}^{2+}$ gel network, hence the $\mathrm{E}^{*}$ of the beads would decrease. However, as the ionic exchange reaches equilibrium, the $\mathrm{E}^{*}$ would stabilize similarly to the diameter.

On the other hand, the $\mathrm{E}^{*}$ of the freeze-dried beads was significantly higher compared to freshly made beads throughout the whole study. 
In contrast the diameter and the mechanical properties of the freeze dried beads do not correlate in the time period studied; these beads also show a decrease in $\mathrm{E}^{*}$ in day 5 , however this was followed by a sharp decrease on day 12 while their diameter remained stable from day 2 until the end of the experiments.

Freeze drying creates microscale porosity by sublimation of ice crystals embedded within the polymeric lattice (Liu et al., 2016; Oikonomopoulou et al., 2011). Hence, as the ice crystals leave the structure, the remaining hydrogel polymer becomes denser, with higher inter-chain entanglement, and a rougher surface (as discussed above). This restructuring may account for the higher $\mathrm{E}^{*}$, as compared to freshly made beads. However, the softening (reduction of $\mathrm{E}^{*}$ ) of the freeze dried beads that occurred on day 12 to day 14 may be due to some slow $\mathrm{Na}^{+}$ion exchange with $\mathrm{Ca}^{2+}$. This is in agreement with the generally expected swelling of calcium alginate gels in physiological media, as seen with the freshly made beads.

\subsection{Limitations}

There were several potential sources of error and variation during the indentation process. Firstly, the position of the bead was optimised (to the highest part of the alginate bead) by the position of the piezo, but this could lead to slight variations of the angle between the cantilever and the bead surface. Secondly, there is a natural variation in bead diameter from electrospraying. Therefore, the standard error was used to show the spread (as error bars) of each bead's mean diameters compared to the bead population mean $\mathrm{E}$ value, due to the variability from batch to batch. In contrast, the standard deviation only depicts the data for each bead rather than the whole population.

This study has successfully measured the swelling behaviour and surface $\mathrm{E}^{*}$ of both freshly made and freeze dried alginate beads. However, it should be noted that the results and behaviour of the alginate beads are specific to high $\mathrm{M}$ alginate used in this study. Previous 
studies have shown that high $G$ alginates present a higher bulk gel strength and are less susceptible to the effect of sodium ions (Martinsen et al., 1989). Despite this, the methods in this study could be replicated with high $\mathrm{G}$ alginates as a potential future avenue to explore.

\section{Conclusions}

In this study, we have produced calcium alginate beads suitable for cell encapsulation and microcarrier purposes. In order to ensure long-term culture in cell culture conditions, the stability of the beads has to be assessed. This was achieved through successful measurement of the local mechanical properties of freeze dried and freshly made alginate beads via AFM microindentations in parallel to measuring the bead diameter by optical microscopy over the course of two weeks. Freshly made beads had a significantly higher $\mathrm{E}^{*}$ on the first day, along with the bead size being significantly smaller. This can be explained because of ion exchange of $\mathrm{Ca}^{2+}$ ions that crosslink the alginate network with monovalent ions such as $\mathrm{Na}^{+}$from DMEM. This weakens the alginate $\mathrm{Ca}^{2+}$ gel network allowing more water into the bead, causing swelling and lowering $E^{*}$. Equilibrium of this ion exchange was reached when swelling did not change significantly from day 2 and was confirmed and consistent with $\mathrm{E}^{*}$ varying nonsignificantly over the remaining time points.

We have also measured the diameter and $\mathrm{E}^{*}$ of electrosprayed beads that underwent a freezedrying cycle. The results of the study showed that re-swelled freeze-dried beads have a higher E* modulus and smaller diameter, in comparison to freshly made beads during the 14-day time frame. This difference could be due to the shrinkage of the alginate beads during freeze drying, which also explains the rougher surface of the beads, smaller diameter and higher average $\mathrm{E}^{*}$ moduli.

Similar to fresh beads, the diameter of freeze dried beads was significantly smaller at day 1 and remained stable after day 2 . On the other hand, $\mathrm{E}^{*}$ of the freeze dried beads was stable in the 
first three time points (day 1, day 5 and day 8). However, there was a significant decrease after day 8 ( $3^{\text {rd }}$ time point). This was possibly due to the slower ion exchange of the freeze dried beads.

The elasticity coupled with diameter changes were conducted within a mimicked cell culture environment and timeframe. Our results provide information on the overall bead stability of alginate-based microbeads for biomedical applications such as microcarrier culture and cell encapsulation.

\section{Conflicts of Interest}

The authors declare no competing financial interest

\section{Acknowledgements}

The authors thank Michelle Kümin for proof-reading and editing of the paper, Alba Piacenti for discussions and Armando Méndez for the graphical abstract

\section{Funding}

This work was supported by China Regenerative Medicine International (CRMI) (CYC, HY), Mexican government and CONACYT (ABB), and the Leverhulme Trust.(JS)

\section{References}


Abubakr, N., Lin, S.X., Chen, X.D., 2009. Effects of Drying Methods on the Release Kinetics of Vitamin B 12 in Calcium Alginate Beads. Dry. Technol. 27, 1258-1265. https://doi.org/10.1080/07373930903267732

Bajpai, S.K., Sharma, S., 2004. Investigation of swelling/degradation behaviour of alginate beads crosslinked with Ca2+ and Ba2+ ions. React. Funct. Polym. 59, 129-140. https://doi.org/10.1016/j.reactfunctpolym.2004.01.002

Barley, J., n.d. Basic Principles of Freeze Drying [WWW Document]. SP Sci. URL https://www.spscientific.com/freeze-drying-lyophilization-basics/ (accessed 6.13.18).

Bidarra, S.J., Barrias, C.C., Granja, P.L., 2014. Injectable alginate hydrogels for cell delivery in tissue engineering. Acta Biomater. 10, 1646-1662. https://doi.org/10.1016/j.actbio.2013.12.006

Cavo, M., Fato, M., Peñuela, L., Beltrame, F., Raiteri, R., Scaglione, S., 2016. Microenvironment complexity and matrix stiffness regulate breast cancer cell activity in a 3D in vitro model. Sci. Rep. 6, 35367. https://doi.org/10.1038/srep35367

Chan, E.-S., Lim, T.-K., Voo, W.-P., Pogaku, R., Tey, B.T., Zhang, Z., 2011. Effect of formulation of alginate beads on their mechanical behavior and stiffness. Particuology 9, 228-234. https://doi.org/10.1016/j.partic.2010.12.002

Chen, A.K.-L., Reuveny, S., Oh, S.K.W., 2013. Application of human mesenchymal and pluripotent stem cell microcarrier cultures in cellular therapy: Achievements and future direction. Biotechnol. Adv. 31, 1032-1046. https://doi.org/10.1016/j.biotechadv.2013.03.006

Choi, B.Y., Park, H.J., Hwang, S.J., Park, J.B., 2002. Preparation of alginate beads for floating drug delivery system : effects of CO 2 gas-forming agents 239, 81-91.

Darrabie, M.D., Kendall, W.F., Opara, E.C., 2006. Effect of alginate composition and gelling cation on micro-bead swelling. J. Microencapsul. 23, 29-37. https://doi.org/10.1080/02652040500286144

Dintwa, E., Tijskens, E., Ramon, H., 2008. On the accuracy of the Hertz model to describe the normal contact of soft elastic spheres. Granul. Matter 10, 209-221. https://doi.org/10.1007/s10035-007-0078-7

Discher, D.E., 2005. Tissue Cells Feel and Respon to the Stiffness of Their Substrate. Science (80-. ). 310, 1139-1143. https://doi.org/10.1126/science.1116995

Domarecka, M., Sokołowski, K., Krasowski, M., Szczesio, A., Bociong, K., Sokołowski, J., Łukomska-Szymańska, M., 2016. Influence of water sorption on the shrinkage stresses of dental composites. J. Stomatol. 69, 412-419. https://doi.org/10.5604/00114553.1225380

Dore, E., 1999. A New Concept of Bioartificial Liver Based on a Fluidized Bed Bioreactor 3, 264-267. https://doi.org/10.1046/j.1526-0968.1999.00152.x 
Drury, J.L., Mooney, D.J., 2003. Hydrogels for tissue engineering: scaffold design variables and applications. Biomaterials 24, 4337-4351. https://doi.org/10.1016/S01429612(03)00340-5

Engler, A.J., Sen, S., Sweeney, H.L., Discher, D.E., 2006. Matrix Elasticity Directs Stem Cell Lineage Specification. Cell 126, 677-689. https://doi.org/10.1016/j.cell.2006.06.044

Freshney, R.., 2011. Biology of Cultured Cells, in: Culture of Animal Cells: A Manual of Basic Technique and Specialized Applications. https://doi.org/10.1002/9780470649367

Gal, A., Nussinovitch, A., 2007. Hydrocolloid Carriers with Filler Inclusionfor Diltiazem Hydrochloride Release. J. Pharm. Sci. 96, 168-178. https://doi.org/https://doi.org/10.1002/jps.20775

Gasperini, L., Maniglio, D., Migliaresi, C., 2013. Microencapsulation of cells in alginate through an electrohydrodynamic process. J. Bioact. Compat. Polym. 28, 413-425. https://doi.org/10.1177/0883911513501599

Gaumann, A., Laudes, M., Jacob, B., Pommersheim, R., Laue, C., Vogt, W., Schrezenmeir, J., 2000. Effect of media composition on long-term in vitro stability of barium alginate and polyacrylic acid multilayer microcapsules 21, 1911-1917. https://doi.org/10.1016/S0142-9612(00)00071-5

Gavara, N., 2016. Combined strategies for optimal detection of the contact point in AFM force-indentation curves obtained on thin samples and adherent cells. Sci. Rep. 6, 1-13. https://doi.org/10.1038/srep21267

Ghasemi-Mobarakeh, L., 2015. Structural properties of scaffolds: Crucial parameters towards stem cells differentiation. World J. Stem Cells 7, 728. https://doi.org/10.4252/wjsc.v7.i4.728

Grant, G.T., Morris, E.R., Rees, D. a., Smith, P.J.C., Thom, D., 1973. Biological interactions between polysaccharides and divalent cations: The egg-box model. FEBS Lett. 32, 195198. https://doi.org/10.1016/0014-5793(73)80770-7

Gröhn, P., Klöck, G., Zimmermann, U., 1997. Collagen-Coated Ba2+ Alginate Microcarriers for the Culture of Anchorage-Dependent Mammalian Cells. Biotechniques 22, 970-975.

Gugerli, R., Cantana, E., Heinzen, C., Stockar, U. Von, Marison, I.W., 2002. Quantitative study of the production and properties of alginate/poly-L-lysine microcapsules. J. Microencapsul. 19, 571-590. https://doi.org/10.1080/02652040210140490

Guilak, F., Cohen, D.M., Estes, B.T., Gimble, J.M., Liedtke, W., Chen, C.S., 2009. Control of Stem Cell Fate by Physical Interactions with the Extracellular Matrix. Cell Stem Cell 5, 17-26. https://doi.org/10.1016/j.stem.2009.06.016

Guo, D., Li, J., Xie, G., Wang, Y., Luo, J., 2014. Elastic properties of polystyrene nanospheres evaluated with atomic force microscopy: Size effect and error analysis. Langmuir 30, 7206-7212. https://doi.org/10.1021/la501485e 
Handorf, A.M., Zhou, Y., Halanski, M. a., Li, W.J., 2015. Tissue stiffness dictates development, homeostasis, and disease progression. Organogenesis 11, 1-15. https://doi.org/10.1080/15476278.2015.1019687

Hari, P.R., Chandy, T., Sharma, C.P., 1996. Chitosan/calcium—alginate beads for oral delivery of insulin. J. Appl. Polym. Sci. 59, 1795-1801. https://doi.org/10.1002/(SICI)1097-4628(19960314)59:11<1795::AIDAPP16>3.3.CO;2-F

Helfricht, N., Doblhofer, E., Bieber, V., Lommes, P., Sieber, V., Scheibel, T., Papastavrou, G., 2017. Probing the adhesion properties of alginate hydrogels: a new approach towards the preparation of soft colloidal probes for direct force measurements. Soft Matter 13, 578-589. https://doi.org/10.1039/C6SM02326F

Hoare, T.R., Kohane, D.S., 2008. Hydrogels in drug delivery: Progress and challenges. Polymer (Guildf). 49, 1993-2007. https://doi.org/10.1016/j.polymer.2008.01.027

Hoffman, A.S., 2012. Hydrogels for biomedical applications. Adv. Drug Deliv. Rev. 43, $3-$ 12. https://doi.org/10.1016/j.addr.2012.09.010

Johnson, K., 1985. Normal contact of elastic solids - Hertz theory, in: Contact Mechanics. Cambridge University Press, pp. 84-106. https://doi.org/10.1017/CBO9781139171731.005

Kim, B.S., Choi, Y.H., Choi, C.Y., Kim, B.G., 1992. Mammalian cell cultivation on serumcoated microcarriers. Biotechnol. Tech. 6, 347-352. https://doi.org/10.1007/BF02439324

Kleinberger, R.M., Burke, N. a D., Dalnoki-Veress, K., Stöver, H.D.H., 2013. Systematic study of alginate-based microcapsules by micropipette aspiration and confocal fluorescence microscopy. Mater. Sci. Eng. C 33, 4295-4304. https://doi.org/10.1016/j.msec.2013.06.033

Krokida, M.K., Karathanos, V.T., 1998. Effect of Freeze-drying Conditions on Shrinkage and Porosity of Dehydrated Agricultural Products. J. Food Eng. 369-380. https://doi.org/10.1177/0734282906298643

Labconco, 2010. A Guide to Freeze Drying for the Laboratory. https://doi.org/10.1017/CBO9781107415324.004

Landau, D., Lifshitz, E.., 1970. Theory of elasticity. Butterworth-Heinemann.

Lechanteur, C., 2014. Large-Scale Clinical Expansion of Mesenchymal Stem Cells in the GMP-Compliant, Closed Automated Quantum ${ }^{\circledR}$ Cell Expansion System: Comparison with Expansion in Traditional T-Flasks. J. Stem Cell Res. Ther. 04, 1-11. https://doi.org/10.4172/2157-7633.1000222

Lee, C.S.D., Moyer, H.R., Gittens I., R. a., Williams, J.K., Boskey, A.L., Boyan, B.D., Schwartz, Z., 2010. Regulating in vivo calcification of alginate microbeads. Biomaterials 31, 4926-4934. https://doi.org/10.1016/j.biomaterials.2010.03.001 
Lee, K.Y., Mooney, D.J., 2012. Alginate: properties and biomedical applications. Prog. Polym. Sci. 37, 106-126. https://doi.org/10.1016/j.progpolymsci.2011.06.003

Lekka, M., Sainz-Serp, D., Kulik, A.J., Wandrey, C., 2004. Hydrogel Microspheres: Influence of Chemical Composition on Surface Morphology, Local Elastic Properties, and Bulk Mechanical Characteristics. Langmuir 20, 9968-9977. https://doi.org/10.1021/la048389h

Liu, G., Hu, Z., Guan, R., Zhao, Y., Zhang, H., Zhang, B., 2016. Efficient removal of methylene blue in aqueous solution by freeze-dried calcium alginate beads. Korean $\mathrm{J}$. Chem. Eng. 33, 3141-3148. https://doi.org/10.1007/s11814-016-0177-4

Markert, C.D., Guo, X., Skardal, A., Wang, Z., Bharadwaj, S., Zhang, Y., Bonin, K., Guthold, M., 2013. Characterizing the micro-scale elastic modulus of hydrogels for use in regenerative medicine. J. Mech. Behav. Biomed. Mater. 27, 115-127. https://doi.org/10.1016/j.jmbbm.2013.07.008

Markvicheva, E., Grandfils, C., 2004. Microcarriers for Animal Cell Culture, in: Fundamentals of Cell Immobilisation Biotechnology. pp. 141-161. https://doi.org/10.1007/978-94-017-1638-3_8

Martinsen, A., Skjak-Braek, G., Smidsrød, O., 1989. Alginate as Immobilization Material: I. Correlation between Chemical and Physical Properties of Alginate Gel Beads. Biotechnol. Bioeng. 33, 79-89. https://doi.org/10.1002/bit.260330111

Mørch, Ä.A., Donati, I., Strand, B.L., Skja, G., 2006. Effect of Ca2 + , Ba2 + , and Sr2 + on Alginate Microbeads 7, 1471-1480. https://doi.org/10.1021/bm060010d

Nunamaker, E.A., Purcell, E.K., Kipke, D.R., 2007. In vivo stability and biocompatibility of implanted calcium alginate disks. J. Biomed. Mater. Res. A 81, 771-780. https://doi.org/10.1002/jbm.a

Oikonomopoulou, V.P., Krokida, M.K., Karathanos, V.T., 2011. The influence of freeze drying conditions on microstructural changes of food products. Procedia Food Sci. 1, 647-654. https://doi.org/10.1016/j.profoo.2011.09.097

Orive, G., Maria Hernández, R., Rodríguez Gascón, A., Calafiore, R., Swi Chang, T.M., Vos, P. De, Hortelano, G., Hunkeler, D., Lacík, I., Luis Pedraz, J., 2004. History, challenges and perspectives of cell microencapsulation. Trends Biotechnol. 22, 87-92. https://doi.org/10.1016/j.tibtech.2003.11.004

Pasparakis, G., Bouropoulos, N., 2006. Swelling studies and in vitro release of verapamil from calcium alginate and calcium alginate-chitosan beads. Int. J. Pharm. 323, 34-42. https://doi.org/10.1016/j.ijpharm.2006.05.054

Patel, N., Lalwani, D., Gollmer, S., Injeti, E., Sari, Y., Nesamony, J., 2016. Development and evaluation of a calcium alginate based oral ceftriaxone sodium formulation. Prog. Biomater. 5, 117-133. https://doi.org/10.1007/s40204-016-0051-9 
Rambhatla, S., Obert, J.P., Luthra, S., Bhugra, C., Pikal, M.J., 2005. Cake shrinkage during freeze drying: A combined experimental and theoretical study. Pharm. Dev. Technol. 10, 33-40. https://doi.org/10.1081/PDT-200035871

Rehfeldt, F., Engler, A.J., Eckhardt, A., Ahmed, F., Discher, D.E., 2007. Cell responses to the mechanochemical microenvironment-Implications for regenerative medicine and drug delivery. Adv. Drug Deliv. Rev. 59, 1329-1339. https://doi.org/10.1016/j.addr.2007.08.007

Rowley, J. a., Mooney, D.J., 2002. Alginate type and RGD density control myoblast phenotype. J. Biomed. Mater. Res. 60, 217-223. https://doi.org/10.1002/jbm.1287

Saha, K., Keung, A.J., Irwin, E.F., Li, Y., Little, L., Schaffer, D. V., Healy, K.E., 2008. Substrate modulus directs neural stem cell behavior. Biophys. J. 95, 4426-4438. https://doi.org/10.1529/biophysj.108.132217

Serra, M., Correia, C., Malpique, R., Brito, C., Jensen, J., Bjorquist, P., Carrondo, M.J.T., Alves, P.M., 2011. Microencapsulation Technology: A Powerful Tool for Integrating Expansion and Cryopreservation of Human Embryonic Stem Cells. PLoS One 6, e23212. https://doi.org/10.1371/journal.pone.0023212

Shirai, Y., Hashimoto, K., Yamaji, H., Tokashiki, M., 1987. Applied Microbiology Biotechnology Continuous production of monoclonal antibody with immobilized hybridoma cells in an expanded bed fermentor 495-499. https://doi.org/10.1007/BF00253020

Sideridou, I., Tserki, V., Papanastasiou, G., 2003. Study of water sorption, solubility and modulus of elasticity of light-cured dimethacrylate-based dental resins. Biomaterials 24, 655-665. https://doi.org/10.1016/S0142-9612(02)00380-0

Sigma-Aldrich, n.d. Product Information: Dulbecco ’s Modified Eagle’s s Medium ( DME ).

Strand, B.L., Gåserød, O., Kulseng, B., Espevik, T., Skjåk-Baek, G., 2002. Alginatepolylysine-alginate microcapsules: effect of size reduction on capsule properties. J. Microencapsul. 19, 615-30. https://doi.org/10.1080/02652040210144243

Szczypka, M., Splan, D., Woolls, H., Brandwein, H., 2014. Single-use bioreactors and microcarriers. Bioprocess Int. 12, 54-64.

Tay, L.F., Khoh, L.K., Loh, C.S., Khor, E., 1993. Alginate-chitosan coacervation in production of artificial seeds. Biotechnol. Bioeng. 42, 449-54. https://doi.org/10.1002/bit.260420407

Tomkoria, S., Masuda, K., Mao, J., 2007. Nanomechanical properties of alginate-recovered chondrocyte matrices for cartilage regeneration. Proc. Inst. Mech. Eng. Part H J. Eng. Med. 221, 467-473. https://doi.org/10.1243/09544119JEIM205

Wang, C.X., Cowen, C., Zhang, Z., Thomas, C.R., 2005. High-speed compression of single alginate microspheres. Chem. Eng. Sci. 60, 6649-6657.

https://doi.org/10.1016/j.ces.2005.05.052 
Wilson, J.L., McDevitt, T.C., 2013. Stem cell microencapsulation for phenotypic control, bioprocessing, and transplantation. Biotechnol. Bioeng. 110, 667-82.

https://doi.org/10.1002/bit.24802

Yuan, P., Jia, Y., Zhang, L., Zhang, J., Hu, W., Wang, C., 2012. Swelling studies and in vitro release of acemetacin and BSA from alginate gel beads crosslinked with $\mathrm{Ca} 2+$ or $\mathrm{Ba} 2+$. J. Wuhan Univ. Technol. Sci. Ed. 27, 669-674. https://doi.org/10.1007/s11595-0120526-z 